\title{
Systemic Inflammatory Markers and Disease Severity in Chronic Obstructive Pulmonary Disease-The Effect of Acute Exercise and Pulmonary Rehabilitation
}

\author{
Amani I. El Gammal1 ${ }^{*}$, Rob 0’Farrell1', Liam 0’Mahony33, Fergus Shanahan², Kieran Killian4, \\ Terence M. 0'Connor ${ }^{1}$ \\ ${ }^{1}$ Department of Respiratory Medicine, Mercy University Hospital, Cork, Ireland \\ ${ }^{2}$ Alimentary Pharmabiotic Centre, University College Cork, Cork, Ireland \\ ${ }^{3}$ Swiss Institute of Allergy and Asthma Research, University of Zurich, Davos, Switzerland \\ ${ }^{4}$ Department of Respiratory Medicine, McMaster University, Hamilton, Ontario, Canada \\ Email: elgammal@mcmaster.ca
}

Received 7 January 2015; accepted 23 January 2015; published 28 January 2015

Copyright (C) 2015 by authors and Scientific Research Publishing Inc.

This work is licensed under the Creative Commons Attribution International License (CC BY). http://creativecommons.org/licenses/by/4.0/

(c) $\underset{\mathrm{EY}}{\mathrm{Br}}$ Open Access

\section{Abstract}

Background: Decreased physical capacity and increased systemic inflammatory response are frequently observed in patients with chronic obstructive pulmonary disease (COPD). The relationship between the inflammatory response and disease severity and the immunological response to exercise were addressed in COPD. Objective: The first objective was to identify systemic biomarkers and their relationship with COPD severity. The second objective was to examine the effect of both acute exercise and pulmonary rehabilitation on these biomarkers. Methods: Forty subjects participated in the study. Thirty-two patients with moderate or severe COPD and 8 healthy nonsmokers completed the study. Spirometry was preformed. Physical capacity was determined by a progressive symptom-limited cycle ergo meter (incremental) test. Blood samples were analyzed for C-reactive protein (CRP), pro-inflammatory cytokines (IL-6, TNF- $\alpha$ ), pro-fibrotic cytokines (TGF- $\beta$ ) and oxidative burst in circulating leukocytes before and after exercise, and before and after pulmonary rehabilitation. Results: IL-6, CRP, WCC and TGF- $\beta$ were higher in COPD $(p<0.05)$ than eight healthy controls. WCC, IL-6, TNF- $\alpha$, CRP and TGF- $\beta$ were negatively related to forced expiratory volume in $1 \mathrm{~s}\left(\mathrm{FEV}_{1}\right)(\mathrm{r}=\mathbf{0 . 4 0 5 4}, 0.3221,0.1528,0.1846$ and 0.1187 , respectively $)$. Acute exercise increased circulating leucocytes and oxidative stress in both groups $(p=0.000,0.0049$ respectively), while IL-6 was increased in COPD group $((p=0.0115)$ and circulating TNF- $\alpha$ in healthy control $(p=0.0369)$. Pulmonary rehabilitation didn't modify the levels of inflammatory mediators. Conclusions: Reduced lung function is associated with increased levels of systemic in-

\footnotetext{
"Corresponding author.

How to cite this paper: El Gammal, A.I., O'Farrell, R., O'Mahony, L., Shanahan, F., Killian, K. and O'Connor, T.M. (2015) Systemic Inflammatory Markers and Disease Severity in Chronic Obstructive Pulmonary Disease-The Effect of Acute Exercise and Pulmonary Rehabilitation. Open Journal of Respiratory Diseases, 5, 19-31. http://dx.doi.org/10.4236/ojrd.2015.51003
} 
flammatory markers and acute exercise can further increase this inflammatory response. However pulmonary rehabilitation is unlikely to exacerbate systemic inflammation in COPD.

\author{
Keywords
}

\author{
Systemic Inflammation, COPD, Oxidative Stress, Pulmonary Rehabilitation
}

\title{
1. Introduction
}

Chronic obstructive pulmonary disease (COPD) is a complex condition characterised by chronic cough and sputum reflecting airway inflammation and more importantly progressive airflow limitation with variable alveolar destruction. In more recent times systemic inflammation with extra pulmonary manifestations that include muscle wasting has also been identified [1].

Inflammation in COPD is complex involving many different cells and molecules. The extent and severity of inflammation may also be estimated by measurement of oxidative stress and concentrations of inflammatory mediators and acute-phase proteins [2]-[6]. C-reactive protein (CRP), an acute-phase protein synthesized predominantly by hepatocytes in response to tissue damage or inflammation has been reported as a predictor of lung function decline and mortality in COPD [7] [8]. CRP increases the production of pro-inflammatory cytokines [9]. Tumour necrosis factor-alpha (TNF- $\alpha$ ) plays an important role as a mediator of cachexia in cancer, chronic heart failure, and cystic fibrosis [10]. Circulating levels of TNF- $\alpha$ and interleukin-6 (IL-6) are elevated in COPD [11]. Transforming Growth Factor-beta (TGF- $\beta$ ) and oxidative stress are biomarkers that may also play a role in the pathogenesis of COPD. TGF- $\beta$, stored in platelets and released from platelets in inflammatory conditions plays a crucial role in tissue repair [12]. TGF- $\beta$ is elevated in all stages of COPD being highest in GOLD stage 4 [12]. Oxidative stress represents an imbalance between the production of reactive oxygen species (ROS) including free radicals, reactive oxygen and nitrogen species and protective antioxidants (such as superoxide dismutase and glutathione peroxidase) [13]. Oxidative stress is involved in the skeletal muscle dysfunction observed in COPD [14] [15]. Direct measurements of oxidative stress are difficult since ROS/free radicals are highly reactive and also short-lived. Rahman et al. [16] were the first to show evidence of systemic oxidative stress in patients with COPD.

The forced expiratory volume in $1 \mathrm{sec}\left(\mathrm{FEV}_{1}\right)$ is accepted in reflecting the severity of COPD [17]. Capacity for gas transfer, exercise capacity, muscle strength, and symptom severity are additionally required to measure disease severity. However, there is no characterized and accepted systemic biomarker profile for assessing COPD severity and evaluating the effectiveness of treatment. Systemic biomarkers may aid with the assessment of disease severity and even guide therapeutic interventions.

Exercise training is a recognized therapeutic intervention in COPD. Exercise alters both the number and function of cells of the innate immune system [18]. During exercise, muscles release IL-6 and exercise has been shown to provoke the secretion of pro- and anti-inflammatory cytokines, including IL-6 which may attenuate TNF-alpha production [19]-[21]. As patients with COPD demonstrate systemic inflammation at rest, exercise could further increase inflammatory mediators [22].

The intensity, duration and type of exercise can influence immune parameters [23] [24]. Exercise training reduces circulating CRP and other inflammatory markers in healthy people and patients with heart failure [25] [26]. Resistance training has been shown to reduce muscle TNF- $\alpha$ in healthy older subjects [27]. Exercise and rehabilitation in patients with COPD may have similar anti-inflammatory effects [28] [29].

The first objective of the current study was to identify the relationship between a wide range of systemic biomarkers and COPD severity. The second objective was to examine the effect of acute exercise on these biomarkers. The last objective was to examine the effect of pulmonary rehabilitation on these biomarkers. High sensitivity CRP, TNF- $\alpha$, IL-6, TGF- $\beta$, WCC, neutrophils and oxidative stress were measured.

\section{Methods}

\subsection{Study Population}

Forty subjects participated in the study; 32 (27 were male) had stable COPD and 8 were healthy subjects (4 were 
male). Subjects with concomitant diseases such as infection, heart failure, cancer, severe endocrine, hepatic, or renal diseases, and systemic autoimmune or connective tissue disorders were excluded from the study. All patients were stable for at least 3 months. The control subjects with normal pulmonary function had never smoked. The medical treatment of patients at the time of the study mainly included inhaled therapy in the form of long-acting $\beta_{2}$ agonists, anticholinergic and corticosteroids. Four patients were on regular systemic corticosteroids and five were on supplemental oxygen therapy. Written, informed consent was obtained and the study was approved by the Clinical Research Ethics Committee of Cork Teaching Hospitals (ECM 4 (e) 01/08/06). The study was started on the $1^{\text {st }}$ August 2006 and was completed on the $30^{\text {th }}$ June 2008.

\subsection{Pulmonary Function and Cardiopulmonary Exercise Test}

Pulmonary function was performed using a Jaeger Master Screen Pneumo ${ }^{\circledR}$ device (Jaeger Co., Hoechberg, Germany). All subjects completed incremental (5 W/min bicycle test) until exhaustion [19] cardiopulmonary exercise test (CPET) using the Master Screen CPX (ViaSys Healthcare, Hoechberg, Germany). Subjects performed a maximal incremental test. Controls performed a submaximal (endurance) CPET at $75 \%$ of the maximum incremental CPET power output one week later. Endurance time was standardized at $12 \mathrm{~min}$, which was the mean endurance time of the patients with COPD at baseline.

\subsection{The Rehabilitation Program}

Patients attended outpatient pulmonary rehabilitation, which consisted of exercise and education sessions, twice weekly for 8 weeks. In addition to this, patients were required to complete 20 minutes of home exercise each day, five times a week. Each rehabilitation session comprised one hour of exercise followed by an education session. Exercises were a mixture of functional aerobic and resistance activities-walking and cycling, sit to stands, step-ups and upper limb work.

\subsection{Health Status}

Health-related quality of life was measured before and after PR with the Chronic Respiratory Disease Questionnaire (CRDQ), St. George's Respiratory Questionnaire (SGRQ), and hospital anxiety and depression questionnaire [20] [21].

\subsection{Cytokine Measurements}

Plasma and serum were obtained by centrifugation and stored at $-80^{\circ} \mathrm{C}$ until analysis. Samples gathered before and after PR were processed in the same run and measured in duplicate. Analyses were performed using quantitative sensitivity and high-sensitivity sandwich enzyme-linked immune-sorbent assays (ELISA) (R \& D systems, Minneapolis, MN). Detection limits for TNF- $\alpha$, IL-6 and TGF-B were $0.11,0.039$, and $4.61 \mathrm{pg} \cdot \mathrm{mL}^{-1}$, respectively. Inter- and intra-assay precision (coefficients of variances) for these markers were below $7 \%$.

\subsection{Oxidative Stress Measurement}

Fifteen millilitres of venous blood was obtained at rest, at peak exercise, and 30 min later. Cell isolation was performed by dextrane sedimentation followed by Hypaque-Ficoll density centrifugation [22]. Contaminating erythrocytes were lysed in a lysis buffer solution and cells were washed in Hanks Balanced Salt Solution. Viability (by trypan blue exclusion) was greater than $95 \%$. Purity of PMNs was $98 \%$ by cytocentrifugation and staining.

Production of reactive oxygen species by neutrophil granulocytes in response to stimulation, the oxidative or respiratory burst, was measured in isolated neutrophils. The oxidative response was reflected by measures of free radical production of neutrophils, and the reduced form of glutathione (GSH).

Luminol-enhanced chemiluminescence was measured in 96-well microplates at $37^{\circ} \mathrm{C}$ for $120 \mathrm{~min}$ in a highly sensitive luminometer (Veritas ${ }^{\mathrm{TM}}$ Microplate Luminometer, Turner BioSystems, USA). Per well, $20 \mu \mathrm{L}$ of Luminol $\left(10^{-4} \mathrm{M}\right)$ was added to $100 \mu \mathrm{L}$ of neutrophil suspension $\left(2 \times 10^{6}\right.$ cells per milliliter) that was unstimulated or stimulated with $20 \mu \mathrm{L}$ of phorbol myristate acetate $\left(5 \mu \mathrm{g} \cdot \mathrm{mL}^{-1}\right)$. Luminescence peak height, as a measure for maximum oxygen radical production, was expressed in relative light units per second (RLU $\cdot \mathrm{s}^{-1}$ ). 
GSSG was measured using a fluorimetric method described previously by Hissin [23] which was sufficiently sensitive and reproducible to provide a valid estimate of oxidative stress. All tests were performed and samples were collected at the same time of day.

\subsection{Statistical Analysis}

Linear regression analyses were performed to test the relationship between $\mathrm{FEV}_{1}$ and inflammatory mediators. Repeated measures analysis of variance (ANOVA) was used to analyse differences between control and COPD and all responses to exercise with effects of different time points (baseline, peak and post exercise), group, and the interaction between the two. Statistical significance was taken at the $p<0.05$ level. Statistical significance was taken at the $\mathrm{p}<0.05$ level. Results are presented as means \pm SE. Sizes of effect are presented as a mean difference and its 95\% confidence interval (95\% CI). Analyses were performed using Statistica programme version 12 (STAT, Tulsa, OK, USA).

\section{Results}

\subsection{Baseline Characteristics}

Comparisons between the COPD group and healthy participants are summarised in Table 1. Among the COPD patients there were more males and the average age was higher. COPD group showed moderate to severe airflow obstruction and reduced exercise capacity. As a supplement of severity, four patients were receiving long term low dose oral corticosteroids, 5 were on supplemental oxygen and the poor values of health status questionnaires.

\subsection{Systemic Inflammation in COPD}

Mean values of total circulating leukocytes, neutrophils as well as CRP, IL-6 and TGF-B levels were significantly higher in COPD patients, Figure 1. No significant differences between COPD patients and healthy subjects were measured in TNF- $\alpha$, oxidative stress and GSSG levels.

Table 1. Baseline characteristics.

\begin{tabular}{|c|c|c|c|c|c|}
\hline \multirow[b]{2}{*}{ Variables } & \multicolumn{2}{|c|}{ COPD N = 32} & \multicolumn{2}{|c|}{ Healthy Control N = 8} & \multirow[b]{2}{*}{ p-Value } \\
\hline & Mean \pm SD & Minimum-Maximum & Mean \pm SD & Minimum-Maximum & \\
\hline Male/Female & $25 / 7$ & & $4 / 4$ & & \\
\hline Age, yrs & $66.06 \pm 9.63$ & $42.00-84.00$ & $58.75 \pm 2.31$ & $56.00-62.00$ & 0.041 \\
\hline $\mathrm{BMI}, \mathrm{kg} \cdot \mathrm{m}^{-2}$ & $23.40 \pm 4.65$ & $14.40-31.20$ & $26.00 \pm 6.54$ & $21.90-41.80$ & 0.201 \\
\hline Pack*Years & $65.06 \pm 50.96$ & $3.2-268$ & 0.0 & & 0.001 \\
\hline $\mathrm{FEV}_{1}, \mathrm{~L}$ & $1.04 \pm 0.33$ & $0.44-1.76$ & $3.41 \pm 0.78$ & $2.95-4.77$ & 0.000 \\
\hline $\mathrm{FEV}_{1}, \%$ predicted & $42.04 \pm 17.11$ & $19.20-84.20$ & $126.70 \pm 47.43$ & $89.50-235.60$ & 0.000 \\
\hline $\mathrm{W}_{\max }, \mathrm{W}$ & $43.10 \pm 13.40$ & $21.00-70.00$ & $119.00 \pm 32.74$ & $76.00-169.00$ & 0.000 \\
\hline SGRQ Total & $56.03 \pm 15.36$ & $23.52-84.25$ & & & \\
\hline CRDQ Dyspnoea, points & $11.53 \pm 4.48$ & $0.00-22.00$ & & & \\
\hline CRDQ Fatigue, points & $14.78 \pm 5.66$ & $4.00-25.00$ & & & \\
\hline CRDQ Emotional, points & $29.84 \pm 10.44$ & $7.00-47.00$ & & & \\
\hline CRDQ Mastery, points & $15.91 \pm 5.51$ & $6.00-27.00$ & & & \\
\hline HAD Depression & $7.06 \pm 3.95$ & $0.00-18.00$ & & & \\
\hline HAD Anxiety & $7.57 \pm 4.45$ & $0.00-16.00$ & & & \\
\hline
\end{tabular}



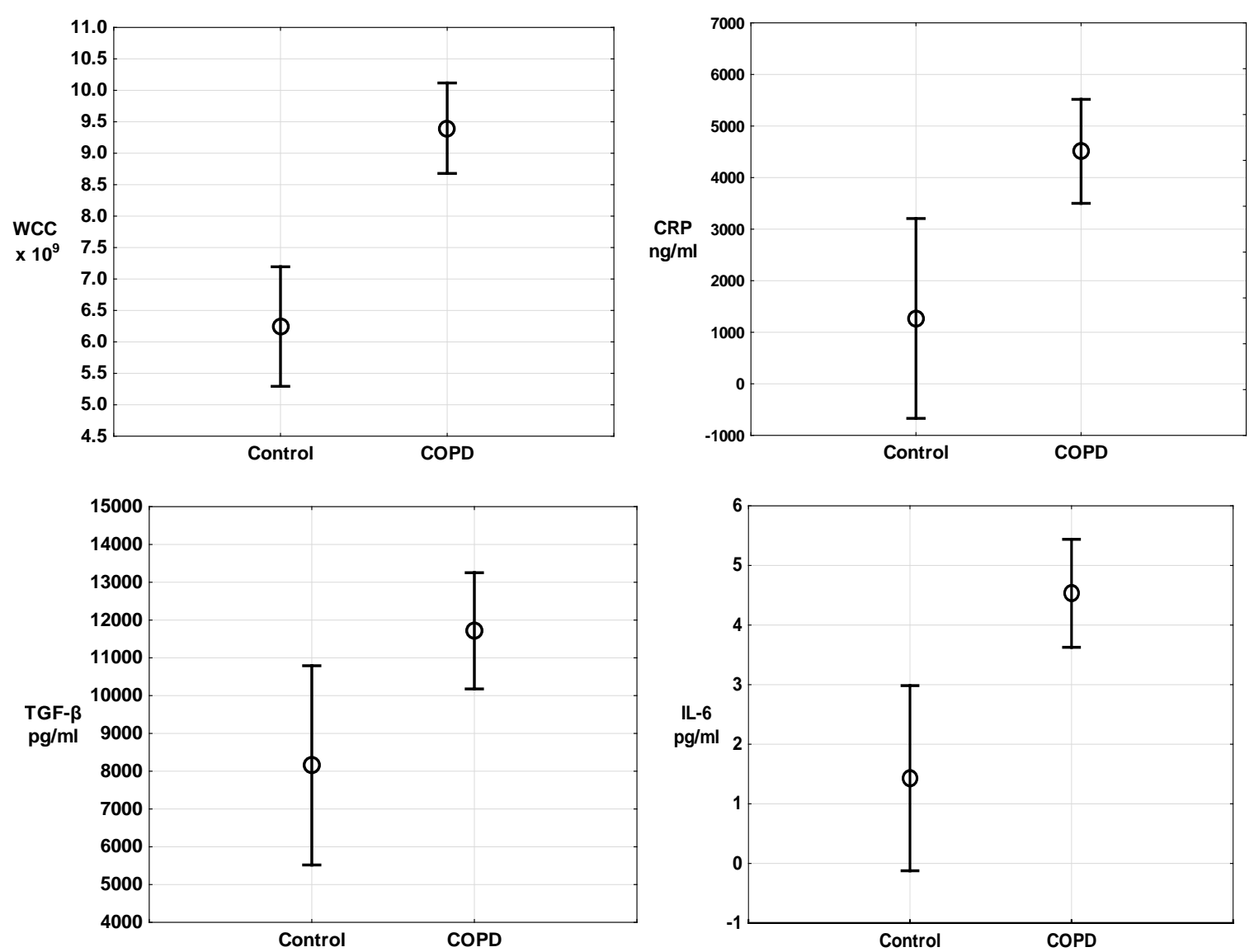

Figure 1. Mean values of baseline leucocytes, CRP, TGF- $\beta$ and IL-6 in healthy subjects and patients with COPD. ${ }^{*} \mathrm{p}<$ 0.05 . Vertical bars denote 0.95 confidence intervals.

\subsection{The Relationship between Disease Severity and Inflammatory Markers}

Linear regression analysis showed a significant negative association between FEV $_{1}$ and WCC, IL-6, CRP, TNF-alpha and TGF- $\beta$, Table 2, Figure 2. No significant relationship was observed between FEV $_{1}$ and oxidative stress or GSSG.

\subsection{Exercise Induced Cytokine Response}

Acute exercise caused an increase of circulating leukocytes in both COPD patients and healthy subjects, followed by a decrease 30 minutes post exercise, Figure 3. Although the mean numbers of leucocytes were significantly higher in COPD patients compared with healthy subjects, the response to exercise was higher in healthy control (group effect $\mathrm{p}=0.0006$ ). Unlike healthy control, the total numbers of leucocyte count in COPD patients failed to return back to baseline level 30 minutes post exercise and that was also reflected in the total neutrophil count.

Acute exercise caused an increase in oxidative burst which continued to increase 30 minutes post exercise and the response was comparable in both groups, Figure 4. GSSG levels were increased in COPD patients but not in the healthy control, Figure 5. There was an increase in IL-6 levels in the COPD group with exercise but not in the healthy group and this effect was more significant in all subjects combined together, Figure 6. Unlike IL-6, TNF- $\alpha$ was increased in the healthy group with exercise but not in COPD patients, Figure 7.

\subsection{Effects of Rehabilitation}

3.5.1. Symptom and Physiologic Responses to Rehabilitation

In patients with COPD, there were statistically significant improvements in all domains of the SGRQ, CRDQ 

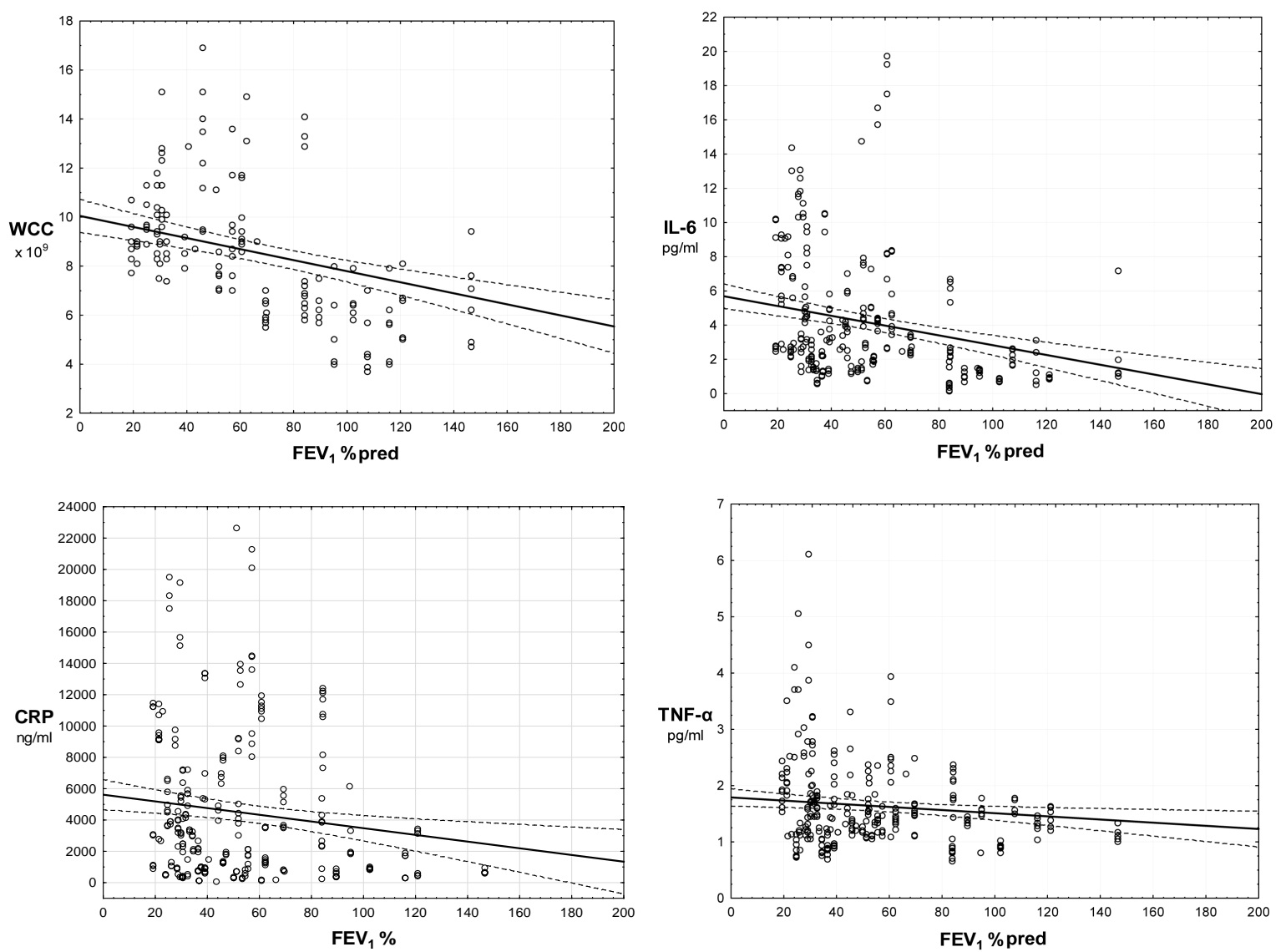

Figure 2. Relationship between inflammatory markers and COPD severity at baseline. COPD, chronic obstructive pulmonary disease. Vertical bars denote 0.95 confidence intervals.

Table 2. Linear regression analysis for all subjects.

\begin{tabular}{|c|c|c|c|c|c|c|c|c|c|}
\hline \multicolumn{10}{|c|}{$\mathbf{Y}=\mathbf{b}_{0}+\mathbf{b}_{1} * \mathrm{FEV}_{1} \%$ predicted } \\
\hline & & $\mathrm{b}^{*}$ & SE & $\mathrm{b}$ & SE & $\mathrm{t}$ & $\mathrm{p}$ & $\mathrm{r}$ & SEE \\
\hline \multirow[t]{2}{*}{ CRP } & $\mathrm{b}_{0}$ & & & 5614.166 & 488.5252 & 11.4921 & 0.0000 & 0.1846 & 4548.6 \\
\hline & $\mathrm{b}_{1}$ & -0.1846 & 0.0610 & -21.380 & 7.0593 & -3.0286 & 0.0027 & & \\
\hline \multirow[t]{2}{*}{ IL-6 } & $\mathrm{b}_{0}$ & & & 5.6868 & 0.3671 & 15.4916 & 0.0000 & 0.3221 & 3.4113 \\
\hline & $\mathrm{b}_{1}$ & -0.3221 & 0.0580 & -0.0286 & 0.0052 & -5.5483 & 0.0000 & & \\
\hline \multirow[t]{2}{*}{ TNF- $\alpha$} & $\mathrm{b}_{0}$ & & & 1.7892 & 0.0784 & 22.8126 & 0.0000 & 0.1528 & 0.7342 \\
\hline & $\mathrm{b}_{1}$ & -0.1528 & 0.0603 & -0.0028 & 0.0011 & -2.5353 & 0.0118 & & \\
\hline \multirow[t]{2}{*}{ TGF- $\beta$} & $\mathrm{b}_{0}$ & & & 11943.70 & 656.1620 & 18.2024 & 0.0000 & 0.1187 & 6097.5 \\
\hline & $\mathrm{b}_{1}$ & -0.1187 & 0.0609 & -17.95 & 9.2079 & -1.9493 & 0.0523 & & \\
\hline \multirow[t]{2}{*}{ OS } & $\mathrm{b}_{0}$ & & & 231.8830 & 10.4992 & 22.0858 & 0.0000 & 0.1409 & 78.535 \\
\hline & $\mathrm{b}_{1}$ & 0.1409 & 0.0746 & 0.2500 & 0.1324 & 1.8880 & 0.0607 & & \\
\hline \multirow[t]{2}{*}{ WCC } & $\mathrm{b}_{0}$ & & & 10.0514 & 0.3434 & 29.2666 & 0.0000 & 0.4054 & 2.403 \\
\hline & $\mathrm{b}_{1}$ & -0.4054 & 0.0727 & -0.0225 & 0.0040 & -5.5739 & 0.0000 & & \\
\hline \multirow[t]{2}{*}{ GSSG } & $\mathrm{b}_{0}$ & & & 97.8143 & 5.0036 & 19.5487 & 0.0000 & 0.0680 & 37.746 \\
\hline & $b_{1}$ & -0.0680 & 0.0744 & -0.0562 & 0.0615 & -0.9144 & 0.3617 & & \\
\hline
\end{tabular}



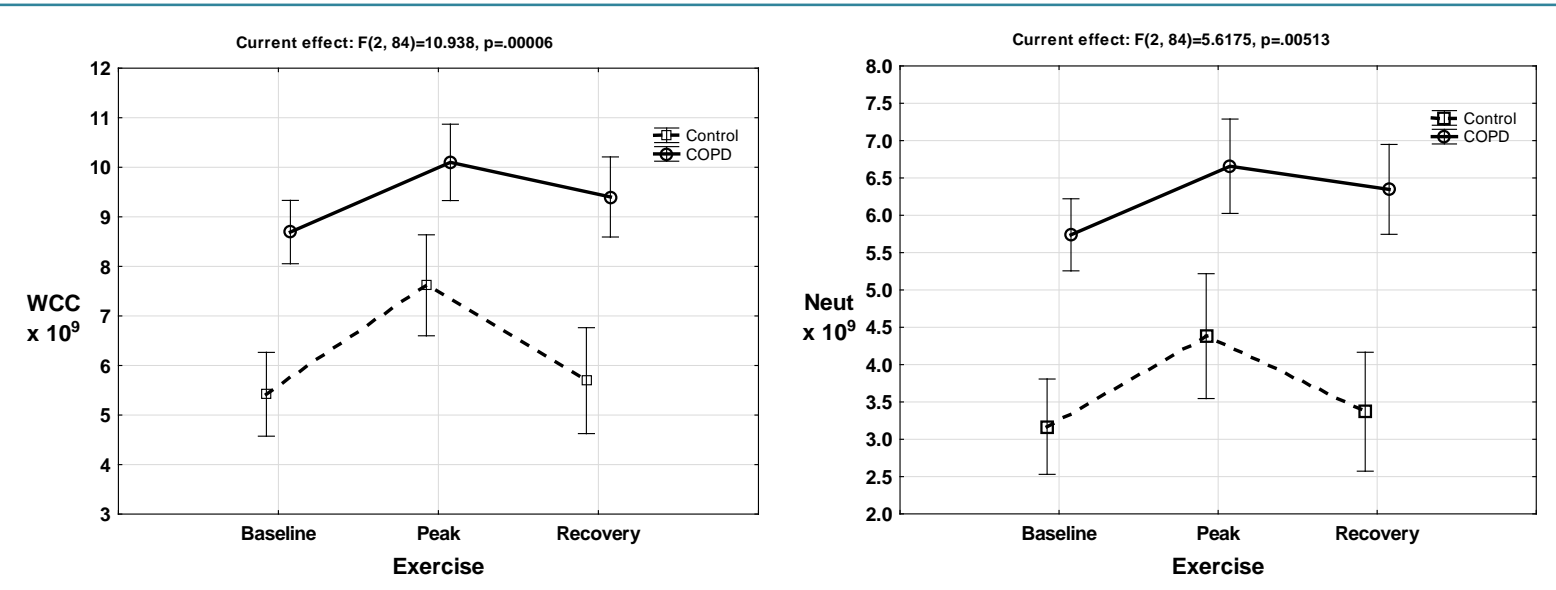

Figure 3. Acute exercise induced leucocytosis in COPD patients and healthy subjects. ${ }^{*} \mathrm{p}=0.000$, vertical bars denote 0.95 confidence intervals. Vertical lines denote $95 \%$ CI.
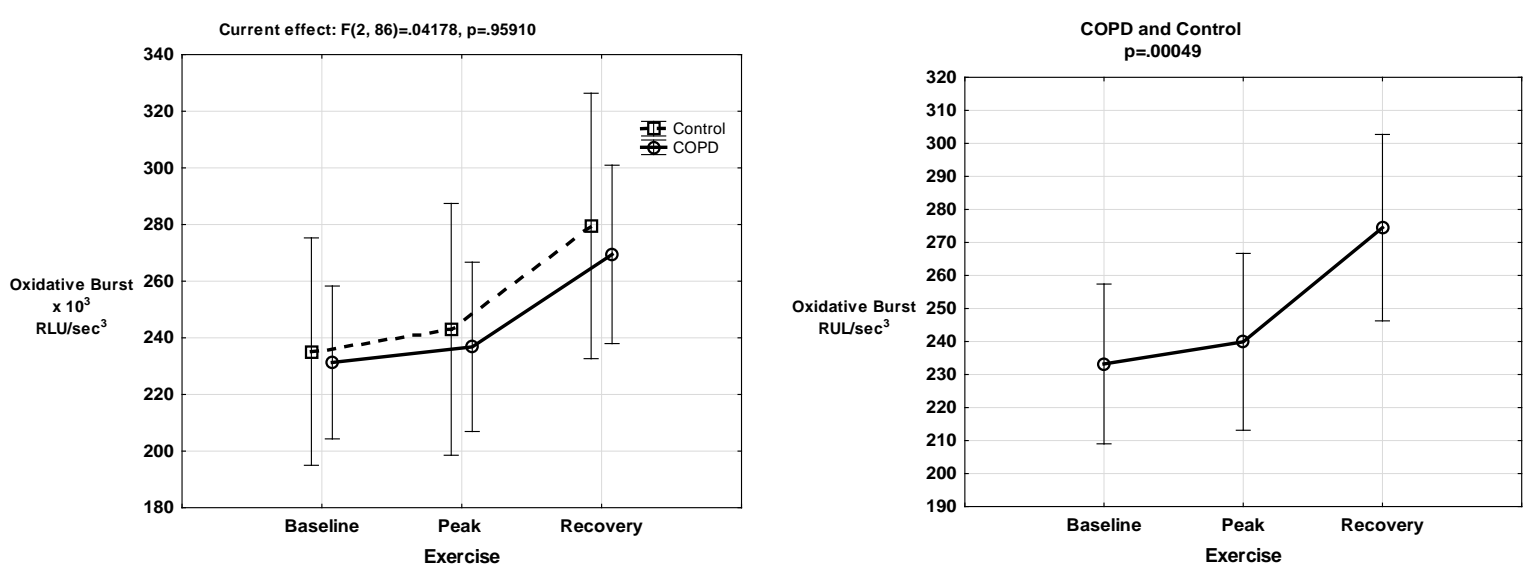

Figure 4. Acute exercise causes an increase in oxidative stress in both COPD patients and healthy subjects. ${ }^{*} \mathrm{p}=0.00713$, ${ }^{* *} \mathrm{p}=0.01065$, vertical bars denote 0.95 confidence intervals.

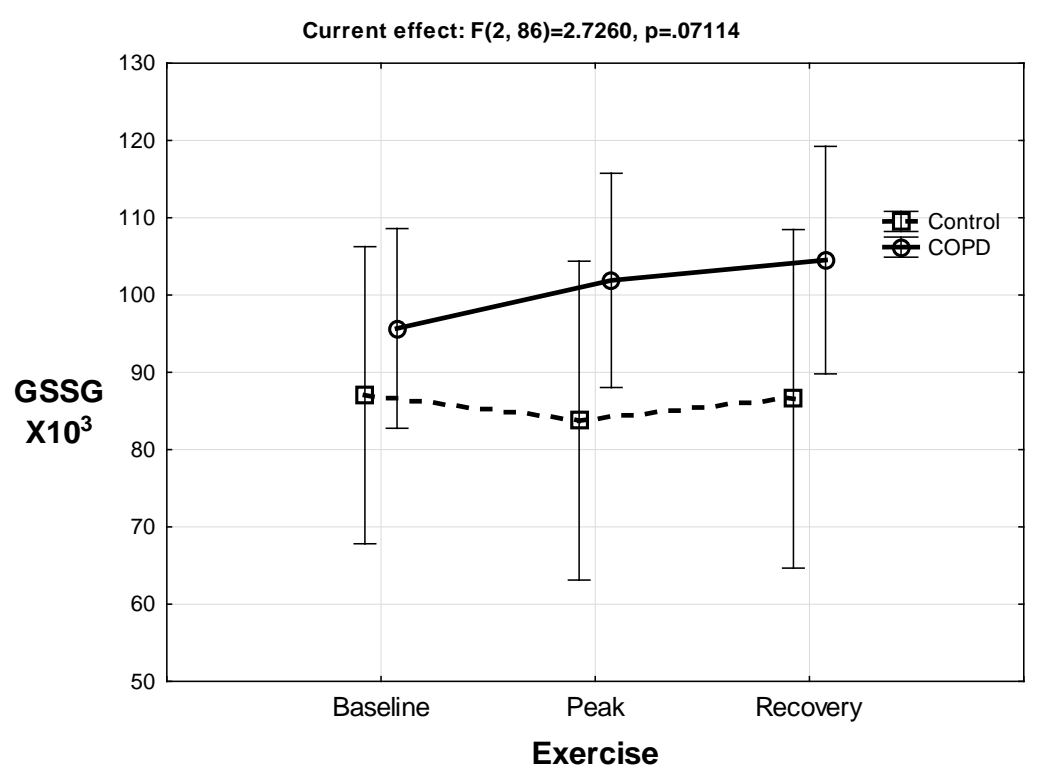

Figure 5. GSSG response to acute exercise. GSSG, glutathione disulfide. * p = 0.00040 . 

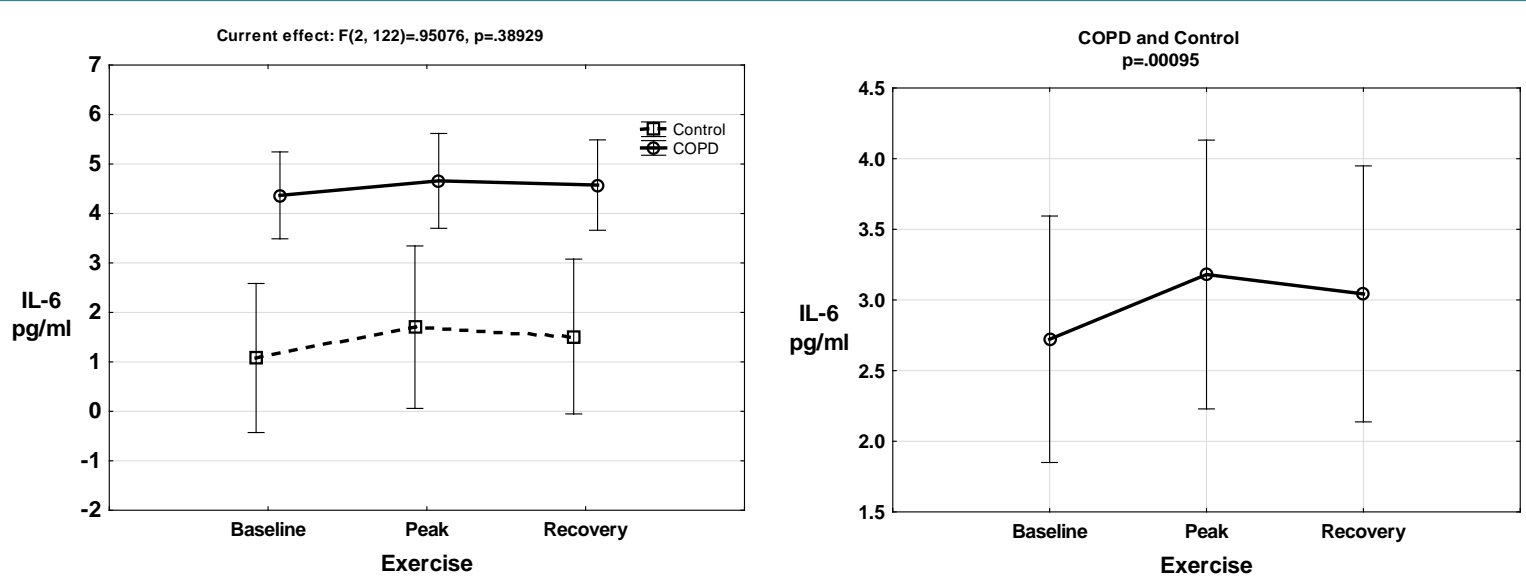

Figure 6. Effect of acute exercise on plasma concentration of IL-6. There was an increase in IL-6 levels in the COPD group with exercise but not in the healthy group and this effect was more significant in all subjects combined together. ${ }^{*} \mathrm{p}$ $=0.01155$, vertical bars denote 0.95 confidence intervals.

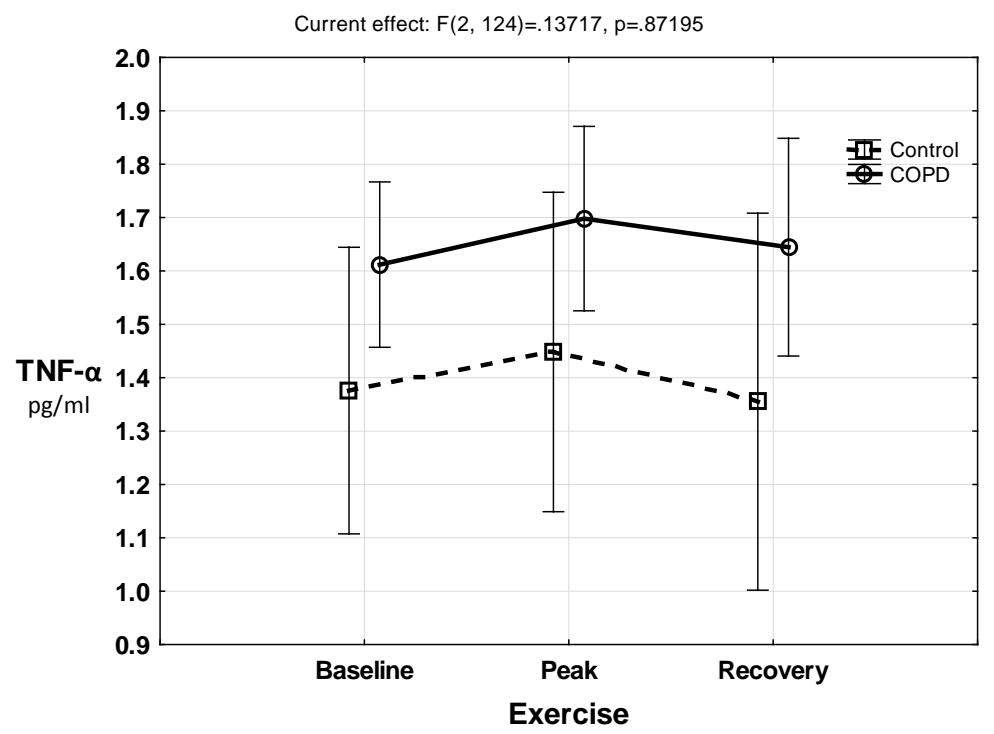

Figure 7. Effect of acute exercise on plasma concentration of TNF $\alpha-{ }^{*} \mathrm{p}=$ 0.03692 , vertical bars denote 0.95 confidence intervals, repeated measures ANOVA.

and HADQ after PR. Among the patients who performed endurance CPET a significant increase in the exercise duration after PR ( $p=0.0003$, 468 vs 815 seconds). No differences in $\mathrm{VO}_{2 \max }$ or $\mathrm{VCO}_{2 \max }$ were noted post rehabilitation.

\subsubsection{The Inflammatory Response to Pulmonary Rehabilitation}

Disappointedly, there was no modification in any of the inflammatory mediators with rehabilitation, Table 3 , Figure 8.

\section{Discussion}

This study provides evidence that stable COPD patients have a pro-inflammatory state, with increased circulating levels of inflammatory cells, cytokines and acute-phase reactants. We were unable to detect differences in circulating TNF- $\alpha$ between healthy controls and patients with COPD. Although TNF is a key stimulus of IL-6 production and similar relationship might be expected, the relatively short serum half-life of TNF compared with IL-6 and CRP may explain the failure to find the same relationship. 


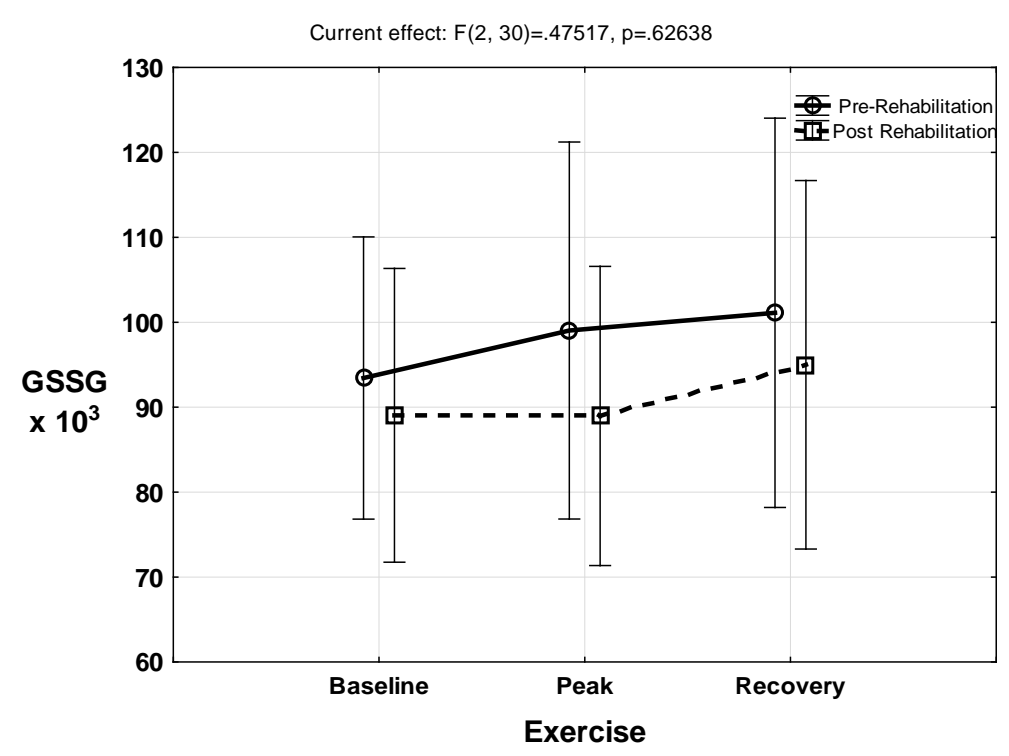

Figure 8. The inflammatory response to pulmonary rehabilitation. GSSG levels were unaltered after exercise but instead there was trend toward reduction in GSSG values but didn't reach statistical significance. GSSG, glutathione disulfide. ${ }^{*} \mathrm{p}=0.04829$.

Table 3. Mean values of inflammatory mediators before and after pulmonary rehabilitation in patients with chronic obstructive pulmonary disease.

\begin{tabular}{ccccccccc}
\hline & \multicolumn{7}{c}{ Pre-Rehabilitation } & \multicolumn{3}{c}{ Post-Rehabilitation } \\
\hline & Mean & $-95 \%$ CI & $+95 \%$ CI & Mean & $-95 \%$ CI & $+95 \%$ CI & p \\
\hline CRP & 4151.87 & 1845.25 & 6458.51 & 5333.179 & 1845.928 & 8820.43 & 0.246 \\
IL-6 & 4.67 & 2.64 & 6.70 & 4.41 & 2.04 & 6.79 & 0.666 \\
TNF & 1.63 & 1.21 & 2.05 & 1.61 & 1.07 & 2.16 & 0.871 \\
TGF-b & 12042.12 & 8720.89 & 15363.35 & 11422.26 & 8321.01 & 14523.52 & 0.616 \\
WCC & 9.31 & 6.33 & 12.29 & 9.24 & 5.90 & 12.58 & 0.910 \\
OS & 246.01 & 171.46 & 320.55 & 249.48 & 186.39 & 312.57 & 0.866 \\
GSSG & 97.86 & 62.49 & 133.23 & 91.00 & 59.86 & 122.14 & 0.247 \\
\hline
\end{tabular}

COPD constitutes an independent factor for the elevation of many of the analyzed systemic biomarkers, which in the case of CRP, TNF- $\alpha$, IL-6, TGF- $\beta$ and WCC is also dependent on severity. We have shown an inverse relationship between the levels of these markers and $\mathrm{FEV}_{1} \%$ predicted. Total leucocyte count had the strongest negative relationship with $\mathrm{FEV}_{1}$.

This inverse relationship between $\mathrm{FEV}_{1}$ and systemic inflammatory markers, especially in the presence of airway obstruction, has been linked to systemic complications in COPD.

\subsection{Inflammatory Response to Acute Exercise in COPD}

Leukocytosis, of which the major component was a raised neutrophil count, was found to be higher following exercise in COPD subjects than in healthy control. However, the number of leukocytes in the COPD patients was already higher at rest and the response was even higher in healthy subjects (group effect $p=0.0006$ ). One can also conclude that the exercise-induced inflammatory response was higher but not exaggerated in COPD. Van Helvoort [22] [30] had showed similar results. "Leucocytosis of exercise" has been described as early as 1893. However, in this study, unlike healthy control, the total WCC didn’t return to baseline post exercise in 
COPD patients suggesting intensified systemic inflammation.

There was an increase in IL-6 with exercise in the COPD group despite the relatively low external workload and the increase was more pronounced when the two groups combined together, Figure 6. Ostrowski et al. [31] showed 128-fold increase after a marathon race compared to baseline levels. Several studies have investigated the response of IL-6 to exercise in COPD patients, but the results are mixed. While Van Helvoort [30] demonstrated an aggravated response of IL-6 in patients with muscle-wasted COPD after maximal exercise, Rabinovich [32] did not.

Unlike IL-6, TNF- $\alpha$ does not seem to increase after exercise in COPD, but increased in healthy subjects. The findings on the response of TNF- $\alpha$ to exercise in COPD patients are inconsistent. Whereas van Helvoort et al. [30] were unable to find any increases in the levels of TNF- $\alpha$ after exercise; Rabinovich [32] did found an increase of circulating TNF- $\alpha$ in COPD after exercise.

TGF- $\beta_{1}$ has been reported to play a major role in the pathogenesis of fibrosis and emphysema in COPD [33]. In the lung, there is increased expression of TGF- $\beta_{1}$ in the airway epithelium of COPD patients which has been associated with enhanced fibrotic airway remodeling [33]. However, the role of circulating TGB- $\beta$ is not clear. There was an increase in TGF- $\beta$ in patients with COPD in this study bur there was no change with exercise while another study showed elevated TGF- $\beta$ levels after extensive exercise [34]. Other studies showed stagedependent correlation between serum TGF- $\beta$ and lung function parameters in patients with COPD [12]. Our observation that median TGF- $\beta_{1}$ serum concentrations were rising with increasing disease severity supports that this mediator plays a role in disease pathogenesis. However, we did not find a significant association between TGF- $\beta_{1}$ and exercise suggesting that the role of TGF- $\beta_{1}$ in the pathogenesis of structural changes in COPD might be more complex.

Oxidative stress is another marker of systemic inflammation and this study showed increased oxidative burst with exercise which was comparable in COPD and control. Another study showed that in COPD patients, but not in healthy subjects, ROS seem to increase after exercise [35].

The most important antioxidant is glutathione (GSH), a low-molecular-weight molecule present in muscle at millimolar concentrations. GSH inactivates ROS and other biologic oxidants, forming glutathione disulfide (GSSG) as the oxidation by-product. GSSG is then recycled enzymatically to GSH. This cycle is interconvertable; GSH is continually being oxidized to GSSG and resynthesized within mammalian cells. The balance between GSH and GSSG can be used to assess overall oxidative stress within the cell [36]. In the current study, acute exercise increased GSSG levels in COPD subjects but not in healthy control. The rise in GSSG indicates that antioxidant buffering is less effective and that activity of unbuffered oxidants is increased in COPD patients. This is in conjunction with other studies [37]-[39].

There was heterogeneity in the acute exercise induced cytokine response between subjects and the evidence available is contradictory. However, this is not very surprising given the several factors that are known to influence acute exercise induced cytokine response including body mass composition, age and gender. The type, level and duration of exercise, for instance, seem to influence the outcome of the cytokine response. The duration of exercise seems to be positively correlated with the amount of cytokine release which might have caused differences between measurements in healthy people and in patient groups, because generally patients are fatigued earlier and thus exercise for a shorter period of time.

\subsection{The Effect of Pulmonary Rehabilitation}

There was no modification to cytokine levels after the 8-week period of rehabilitation.

Rabinovich and associates [40] showed that the 8-wk protocol of high-intensity training had the expected effect in control subjects. Compared with the untrained state, the trained vastus lateralis muscle maintained GSH at significantly higher levels after a bout of exhaustive exercise. Thus, training appeared to increase the efficacy of antioxidant buffering in control subjects as expected [41]. No such benefit was seen in individuals with COPD. GSH concentrations measured after exhaustive exercise were unaltered by training. Worse, training increased the GSSG levels measured after exhaustive exercise. The latter finding is contradictory to the findings in the current study. Acute exercise increased GSSG levels in COPD subjects but not in healthy control, however, after 8-week rehabilitation, GSSG levels were unaltered after exercise but instead there was trend toward reduction in GSSG values but didn’t reach statistical significance, Figure 5.

Mercken reported that PR was associated with reduced oxidative stress after submaximal exercise in patients 
with COPD [28]. In the COPD group in our study, peak exercise samples were taken at exhaustion rather than at the same duration of exercise before PR (isotime). The duration of endurance exercise was 74\% longer after PR $(p=0.0003)$. Measurements of oxidative stress at isotime may have demonstrated significant differences before and after PR, as inflammatory response increases with the intensity and duration of exercise. The type of physical activity and its intensity and duration seem to be highly relevant to differences in the cytokine response to exercise [42].

\subsection{Limitations of the Study}

There are several limitations of the current worth discussing. A relatively small number of healthy subjects were included in the study. Despite the small size, we note the large standard deviations for cytokine response and consistency of our results. Our COPD patient sample is representative of the COPD regularly seen in clinical practice.

Although the statistical model aims to adjust for the possible confounding factors, the existence of some uncontrolled effects cannot be excluded. Our results could also be affected by other drawbacks. Of the COPD patients in our study, almost all patients used inhaled corticosteroids and $12 \%$ used systemic corticosteroids. This could contribute to the underestimation of the difference in systemic biomarkers between COPD patients and control subjects. Nevertheless, the effect of inhaled corticosteroids on inflammatory biomarkers is still controversial. Other chronic conditions, such as chronic heart failure or diabetes, also appear to be associated with a similar systemic inflammatory process. Several studies have described that these disorders are more frequent in COPD patients and, therefore, might also contribute to their pro-inflammatory state. In order to analyze only the effect of COPD as an independent factor, we have carefully excluded these conditions from the present study.

\section{Conclusion}

In conclusion, these data support the now well-established view that systemic inflammation is higher in patients with COPD and that systemic inflammatory mediators are associated with disease severity. Furthermore, exercise-induced inflammatory response was higher but not exaggerated in COPD. Finally, our hypothesis that pulmonary rehabilitation may modify pro-inflammatory mediators, as long-term training in healthy subjects does [43], has not been demonstrated in this study.

\section{Acknowledgements}

This work was supported by the Irish Lung Foundation.

None of the authors have any personal or financial support or author involvement with organizations with financial interest in the subject matter-or any actual or potential conflict of interest.

\section{References}

[1] Celli, B.R. and MacNee, W. (2004) Standards for the Diagnosis and Treatment of Patients with COPD: A Summary of the ATS/ERS Position Paper. European Respiratory Journal, 23, 932-946. http://dx.doi.org/10.1183/09031936.04.00014304

[2] Karadag, F., Kirdar, S., Karul, A.B. and Ceylan, E. (2008) The Value of C-Reactive Protein as a Marker of Systemic Inflammation in Stable Chronic Obstructive Pulmonary Disease. European Journal of Internal Medicine, 19, 104-108. http://dx.doi.org/10.1016/j.ejim.2007.04.026

[3] Fabbri, L.M. and Rabe, K.F. (2007) From COPD to Chronic Systemic Inflammatory Syndrome? Lancet, 370, $797-799$. http://dx.doi.org/10.1016/S0140-6736(07)61383-X

[4] Eagan, T.M., Gabazza, E.C., D’Alessandro-Gabazza, C., Gil-Bernabe, P., Aoki, S., Hardie, J.A., Bakke, P.S. and Wagner, P.D. (2012) TNF-Alpha Is Associated with Loss of Lean Body Mass Only in Already Cachectic COPD Patients. Respiratory Research, 13, 48. http://dx.doi.org/10.1186/1465-9921-13-48

[5] Agusti, A., Edwards, L.D., Rennard, S.I., MacNee, W., Tal-Singer, R., Miller, B.E., Vestbo, J., Lomas, D.A., Calverley, P.M., Wouters, E., Crim, C., Yates, J.C., Silverman, E.K., Coxson, H.O., Bakke, P., Mayer, R.J. and Celli, B. (2012) Persistent Systemic Inflammation Is Associated with Poor Clinical Outcomes in COPD: A Novel Phenotype. PLoS One, 7, e37483. http://dx.doi.org/10.1371/journal.pone.0037483

[6] Dickens, J.A., Miller, B.E., Edwards, L.D., Silverman, E.K., Lomas, D.A. and Tal-Singer, R. (2011) COPD Association and Repeatability of Blood Biomarkers in the ECLIPSE Cohort. Respiratory Research, 12, 146. 
http://dx.doi.org/10.1186/1465-9921-12-146

[7] Higashimoto, Y., Iwata, T., Okada, M., Satoh, H., Fukuda, K. and Tohda, Y. (2009) Serum Biomarkers as Predictors of Lung Function Decline in Chronic Obstructive Pulmonary Disease. Respiratory Medicine, 103, 1231-1238. http://dx.doi.org/10.1016/j.rmed.2009.01.021

[8] de Torres, J.P., Cordoba-Lanus, E., Lopez-Aguilar, C., de Muros, F.M., de Montejo, G.A., Aguirre-Jaime, A., Celli, B.R. and Casanova, C. (2006) C-Reactive Protein Levels and Clinically Important Predictive Outcomes in Stable COPD Patients. European Respiratory Journal, 27, 902-907.

[9] Pasceri, V., Willerson, J.T. and Yeh, E.T. (2000) Direct Proinflammatory Effect of C-Reactive Protein on Human Endothelial Cells. Circulation, 102, 2165-2168. http://dx.doi.org/10.1161/01.CIR.102.18.2165

[10] Nussinovitch, U. and Shoenfeld, Y. (2007) Cachexia, Malignancy and Tumor Necrosis Factor Alpha (TNF-Alpha). Harefuah, 146, 349-351, 406.

[11] Heidari, B. (2012) The Importance of C-Reactive Protein and Other Inflammatory Markers in Patients with Chronic Obstructive Pulmonary Disease. Caspian Journal of Internal Medicine, 3, 428-435.

[12] Stoll, P., Wuertemberger, U., Bratke, K., Zingler, C., Virchow, J.C. and Lommatzsch, M. (2012) Stage-Dependent Association of BDNF and TGF- $\beta_{1}$ with Lung Function in Stable COPD. Respiratory Research, 13, 116. http://dx.doi.org/10.1186/1465-9921-13-116

[13] MacNee, W. and Rahman, I. (2001) Is Oxidative Stress Central to the Pathogenesis of Chronic Obstructive Pulmonary Disease? Trends in Molecular Medicine, 7, 55-62. http://dx.doi.org/10.1016/S1471-4914(01)01912-8

[14] Barreiro, E., de la Puente, B., Minguella, J., Corominas, J.M., Serrano, S., Hussain, S.N. and Gea, J. (2005) Oxidative Stress and Respiratory Muscle Dysfunction in Severe Chronic Obstructive Pulmonary Disease. American Journal of Respiratory and Critical Care Medicine, 171, 1116-1124. http://dx.doi.org/10.1164/rccm.200407-887OC

[15] Barreiro, E., Peinado, V.I., Galdiz, J.B., Ferrer, E., Marin-Corral, J., Sanchez, F., Gea, J. and Barbera, J.A. (2010) Cigarette Smoke-Induced Oxidative Stress: A Role in Chronic Obstructive Pulmonary Disease Skeletal Muscle Dysfunction. American Journal of Respiratory and Critical Care Medicine, 182, 477-488. http://dx.doi.org/10.1164/rccm.200908-12200C

[16] Rahman, I., Morrison, D., Donaldson, K. and MacNee, W. (1996) Systemic Oxidative Stress in Asthma, COPD, and Smokers. American Journal of Respiratory and Critical Care Medicine, 154, 1055-1060. http://dx.doi.org/10.1164/ajrccm.154.4.8887607

[17] Kostikas, K., Bakakos, P., Papiris, S., Stolz, D. and Celli, B.R. (2013) Systemic Biomarkers in the Evaluation and Management of COPD Patients: Are We Getting Closer to Clinical Application? Current Drug Targets, 14, 177-191. http://dx.doi.org/10.2174/1389450111314020005

[18] Walsh, N.P., Gleeson, M., Shephard, R.J., Gleeson, M., Woods, J.A., Bishop, N.C., Fleshner, M., Green, C., Pedersen, B.K., Hoffman-Goetz, L., Rogers, C.J., Northoff, H., Abbasi, A. and Simon, P. (2011) Position Statement. Part One: Immune Function and Exercise. Exercise Immunology Review, 17, 6-63.

[19] Timmons, B.W. (2005) Paediatric Exercise Immunology: Health and Clinical Applications. Exercise Immunology Review, 11, 108-144.

[20] Petersen, A.M. and Pedersen, B.K. (2006) The Role of IL-6 in Mediating the Anti-Inflammatory Effects of Exercise. Journal of Physiology and Pharmacology, 57, 43-51.

[21] Starkie, R., Ostrowski, S.R., Jauffred, S., Febbraio, M. and Pedersen, B.K. (2003) Exercise and IL-6 Infusion Inhibit Endotoxin-Induced TNF-Alpha Production in Humans. FASEB Journal, 17, 884-886.

[22] van Helvoort, H.A., van de Pol, M.H., Heijdra, Y.F. and Dekhuijzen, P.N. (2005) Systemic Inflammatory Response to Exhaustive Exercise in Patients with Chronic Obstructive Pulmonary Disease. Respiratory Medicine, 99, 1555-1567. http://dx.doi.org/10.1016/j.rmed.2005.03.028

[23] Ploeger, H.E., Takken, T., de Greef, M.H. and Timmons, B.W. (2009) The Effects of Acute and Chronic Exercise on Inflammatory Markers in Children and Adults with a Chronic Inflammatory Disease: A Systematic Review. Exercise Immunology Review, 15, 6-41.

[24] Pedersen, B.K. and Hoffman-Goetz, L. (2000) Exercise and the Immune System: Regulation, Integration, and Adaptation. Physiological Reviews, 80, 1055-1081.

[25] Mattusch, F., Dufaux, B., Heine, O., Mertens, I. and Rost, R. (2000) Reduction of the Plasma Concentration of C-Reactive Protein Following Nine Months of Endurance Training. International Journal of Sports Medicine, 21, 21-24. http://dx.doi.org/10.1055/s-2000-8852

[26] Kasapis, C. and Thompson, P.D. (2005) The Effects of Physical Activity on Serum C-Reactive Protein and Inflammatory Markers: A Systematic Review. Journal of the American College of Cardiology, 45, 1563-1569. http://dx.doi.org/10.1016/j.jacc.2004.12.077 
[27] Greiwe, J.S., Cheng, B., Rubin, D.C., Yarasheski, K.E. and Semenkovich, C.F. (2001) Resistance Exercise Decreases Skeletal Muscle Tumor Necrosis Factor Alpha in Frail Elderly Humans. FASEB Journal, 15, 475-482. http://dx.doi.org/10.1096/fj.00-0274com

[28] Mercken, E.M., Hageman, G.J., Schols, A.M., Akkermans, M.A., Bast, A. and Wouters, E.F. (2005) Rehabilitation Decreases Exercise-Induced Oxidative Stress in Chronic Obstructive Pulmonary Disease. American Journal of Respiratory and Critical Care Medicine, 172, 994-1001. http://dx.doi.org/10.1164/rccm.200411-1580OC

[29] Garrod, R., Ansley, P., Canavan, J. and Jewell, A. (2007) Exercise and the Inflammatory Response in Chronic Obstructive Pulmonary Disease (COPD)—Does Training Confer Anti-Inflammatory Properties in COPD? Medical Hypotheses, 68, 291-298. http://dx.doi.org/10.1016/j.mehy.2006.07.028

[30] van Helvoort, H.A., Heijdra, Y.F., de Boer, R.C., Swinkels, A., Thijs, H.M. and Dekhuijzen, P.N. (2007) Six-Minute Walking-Induced Systemic Inflammation and Oxidative Stress in Muscle-Wasted COPD Patients. Chest, 131, 439-445. http://dx.doi.org/10.1378/chest.06-1655

[31] Ostrowski, K., Rohde, T., Asp, S., Schjerling, P. and Pedersen, B.K. (1999) Pro- and Anti-Inflammatory Cytokine Balance in Strenuous Exercise in Humans. Journal of Physiology, 515, 287-291. http://dx.doi.org/10.1111/j.1469-7793.1999.287ad.x

[32] Rabinovich, R.A., Figueras, M., Ardite, E., Carbo, N., Troosters, T., Filella, X., Barbera, J.A., Fernandez-Checa, J.C., Argiles, J.M. and Roca, J. (2003) Increased Tumour Necrosis Factor-Alpha Plasma Levels during Moderate-Intensity Exercise in COPD Patients. European Respiratory Journal, 21, 789-794. http://dx.doi.org/10.1183/09031936.03.00042702

[33] Nakanishi, H., Sugiura, T., Streisand, J.B., Lonning, S.M. and Roberts Jr., J.D. (2007) TGF- $\beta$-Neutralizing Antibodies Improve Pulmonary Alveologenesis and Vasculogenesis in the Injured Newborn Lung. American Journal of Physiology-Lung Cellular and Molecular Physiology, 293, L151-L161. http://dx.doi.org/10.1152/ajplung.00389.2006

[34] Hering, S., Jost, C., Schulz, H., Hellmich, B., Schatz, H. and Pfeiffer, A. (2002) Circulating Transforming Growth Factor $\beta 1$ (TGF $\beta 1$ ) Is Elevated by Extensive Exercise. European Journal of Applied Physiology, 86, 406-410. http://dx.doi.org/10.1007/s00421-001-0537-5

[35] Van Helvoort, H.A., Heijdra, Y.F., Thijs, H.M., Vina, J., Wanten, G.J. and Dekhuijzen, P.N. (2006) Exercise-Induced Systemic Effects in Muscle-Wasted Patients with COPD. Medicine \& Science in Sports \& Exercise, 38, 1543-1552. http://dx.doi.org/10.1249/01.mss.0000228331.13123.53

[36] Schafer, F.Q. and Buettner, G.R. (2001) Redox Environment of the Cell as Viewed through the Redox State of the Glutathione Disulfide/Glutathione Couple. Free Radical Biology and Medicine, 30, 1191-1212. http://dx.doi.org/10.1016/S0891-5849(01)00480-4

[37] Mercken, E.M., Calvert, L.D., Singh, S.J., Hageman, G.J., Schols, A.M. and Steiner, M.C. (2009) Dichloroacetate Modulates the Oxidative Stress and Inflammatory Response to Exercise in COPD. Chest, 136, 744-751. http://dx.doi.org/10.1378/chest.08-2890

[38] Heunks, L.M., Vina, J., van Herwaarden, C.L., Folgering, H.T., Gimeno, A. and Dekhuijzen, P.N. (1999) Xanthine Oxidase Is Involved in Exercise-Induced Oxidative Stress in Chronic Obstructive Pulmonary Disease. American Journal of Physiology, 277, R1697-R1704.

[39] Vina, J., Servera, E., Asensi, M., Sastre, J., Pallardo, F.V., Ferrero, J.A., Garcia-De-La-Asuncion, J., Anton, V. and Marin, J. (1996) Exercise Causes Blood Glutathione Oxidation in Chronic Obstructive Pulmonary Disease: Prevention by $\mathrm{O}_{2}$ Therapy. Journal of Applied Physiology, 81, 2198-2202.

[40] Rabinovich, R.A., Ardite, E., Troosters, T., Carbo, N., Alonso, J., Gonzalez de Suso, J.M., Vilaro, J., Barbera, J.A., Polo, M.F., Argiles, J.M., Fernandez-Checa, J.C. and Roca, J. (2001) Reduced Muscle Redox Capacity after Endurance Training in Patients with Chronic Obstructive Pulmonary Disease. American Journal of Respiratory and Critical Care Medicine, 164, 1114-1118. http://dx.doi.org/10.1164/ajrccm.164.7.2103065

[41] Powers, S.K., Ji, L.L. and Leeuwenburgh, C. (1999) Exercise Training-Induced Alterations in Skeletal Muscle Antioxidant Capacity: A Brief Review. Medicine \& Science in Sports \& Exercise, 31, 987-997. http://dx.doi.org/10.1097/00005768-199907000-00011

[42] Pedersen, B.K., Ostrowski, K., Rohde, T. and Bruunsgaard, H. (1998) The Cytokine Response to Strenuous Exercise. Canadian Journal of Physiology and Pharmacology, 76, 505-511. http://dx.doi.org/10.1139/y98-055

[43] Jankord, R. and Jemiolo, B. (2004) Influence of Physical Activity on Serum IL-6 and IL-10 Levels in Healthy Older Men. Medicine \& Science in Sports \& Exercise, 36, 960-964. http://dx.doi.org/10.1249/01.MSS.0000128186.09416.18 
Scientific Research Publishing (SCIRP) is one of the largest Open Access journal publishers. It is currently publishing more than 200 open access, online, peer-reviewed journals covering a wide range of academic disciplines. SCIRP serves the worldwide academic communities and contributes to the progress and application of science with its publication.

Other selected journals from SCIRP are listed as below. Submit your manuscript to us via either submit@scirp.org or Online Submission Portal.
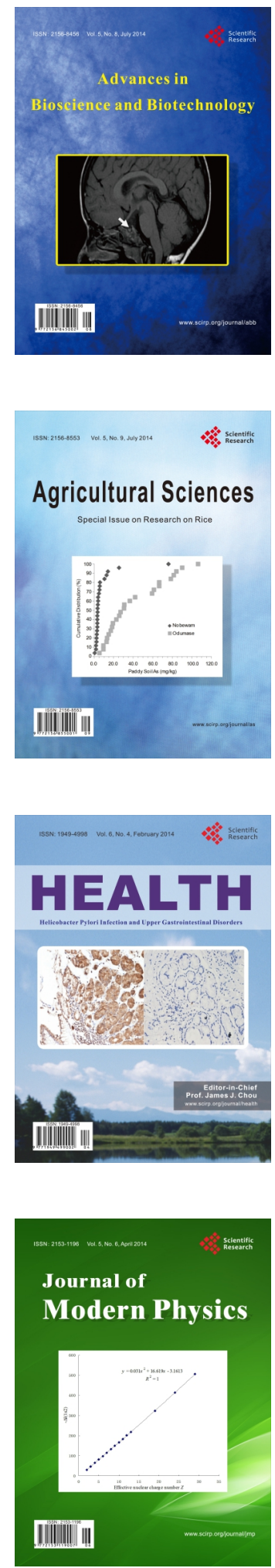
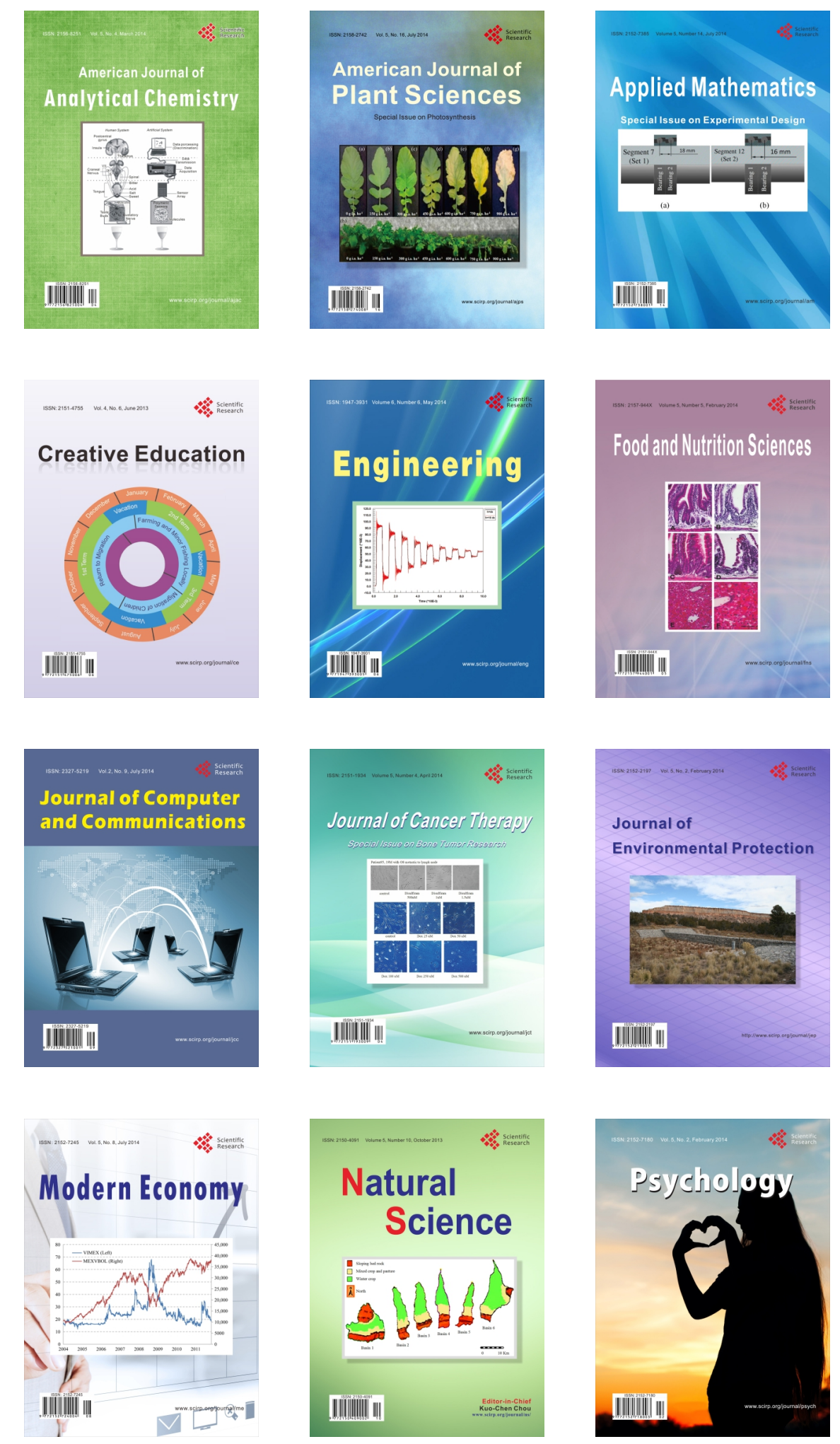